\title{
Comment
}

\section{NEW IDEAS: ORDINARY IS EXTRAORDINARY}

Michael Dodson ${ }^{1,4}$, Melinda Fernyhough ${ }^{1}$, Jose Antonio ${ }^{2}$, and Luke Bucci ${ }^{3}$

Muscle Biology Laboratory, Department of Animal Sciences, Washington State University ${ }^{1}$, Javalution, Fort Lauderdale, $\mathrm{FL}^{2}$, and Weider Nutrition International, Salt Lake City, UT ${ }^{2}$ Sports Nutrition Review Journal. 1(1):67-68, 2004. Address correspondence to dodson@wsu.edu

Received June 2, 2004/Accepted June 2, 2004/Published (online)

\begin{abstract}
With the initial issue of this journal, a new challenge has been offered to the world of sports nutrition: initiate "team oriented" research and clinical trials in order to make dynamic progress in terms of understanding and applying nutrition principals to the field of competitive sports. It is our further challenge that these teams think "outside the box" in terms of their approach to elucidating new concepts through which nutritional interventions might play a role in the regulation of muscle growth and repair, athletic performance and endurance, and mental acuity. What was once thought of as extraordinary might now be approached as ordinary, if the correct composition of "teams" were formed. Sports Nutrition Review Journal. 1(1):67-68, 2004.
\end{abstract}

Key Words: sport nutrition, research, new regulatory mechanisms

\section{INTRODUCTION}

After reading the first issue of Sports Nutrition Review Journal we immediately thought that one area was missing from the introductory articles. The formation of a team approach to nutritional/performance problem solving is needed, with at least one member of the supporting team being extraordinary. What we propose by this is that at least one member of the sports nutrition "team" needs to be capable of thinking in an almost eccentric manner.....with extraordinary ideas being an ordinary occurrence. By having one member performing in this capacity, progress will be made (we believe) at an amazing rate. For this idea, we offer one example: Many of us have been taught that muscles grow in specific ways, with little capacity for postnatal hyperplasia and only minute ability to fully regenerate itself when damaged. Furthermore, we have commonly been told that only a small number of factors (ex. growth hormone, steroids) may directly regulate muscle fiber hypertrophy.

Additionally, it has been "beat into us" that as we age, muscle mass will automatically decrease (a process commonly called sarcopenia) - and that little can be done for senile muscular atrophy, except exercise.

With the huge number of research papers appearing each day in the scientific literature, there seems to be mounting evidence that some of these "ordinary" and commonly accepted ideas may not be as true as once thought. What if postnatal skeletal muscle could increase numbers of cells (through some as yet undetermined mechanism)? What if nutrients (themselves) could regulate muscle growth dynamics - with the correct exercise regimen? What if we could actually retain our muscle mass as we get older?

Who will discover these types of potentially important physiological mechanisms unless 
someone thinks in an extraordinary manner? Further, what will it take to form research, clinical, and performance "teams" unless someone can see through the present myths regarding muscle growth, nutritional dogma, and performance limitations? We propose that this journal and members of this society can make a huge difference in the current status of physiology, nutrition, and exercise interactions - by thinking that the ordinary is actually extraordinary. 